\title{
Comparative Study of Anaesthetic Properties of Bupivacaine Alone And A Combination of Dexamethasone And Bupivacaine, for Interscalene Brachial Plexus Block, in Upper Limb Surgery
}

\author{
Dr. Isha Bijarnia ${ }^{1}$, Dr.Alaka Purohit ${ }^{2}$, Dr. Rakesh Kumar ${ }^{3}$ \\ ${ }^{1}$ Senior Resident,${ }^{2}$ Professor, Department Of Anaesthesia, SMS Medical College \& Hospital, Jaipur, \\ Rajasthan, India \\ , Junior Specialist, Department Of Orthopedics, SMS Medical College \& Hospital, Jaipur, Rajasthan, India
}

\begin{abstract}
Background: Peripheral nerve blocks are used as the sole anaesthetic technique to facilitate painless surgery supplemented with monitored anaesthesia care. People have tried mixing local anaesthetic with adjuvant drugs in an attempt to prolong analgesia duration. Aims of this study is to determine the effects of dexamethasone, when added to bupivacaine on the onset, duration of sensory blockade, motor blockade and evaluated its side effects during interscalene brachial plexus block.

Method: It was a randomized, double blind, interventional type, hospital based controlled study. 60 patients were randomized into two groups. In control group bupivacaine $140 \mathrm{mg}(28 \mathrm{ml}$ of $0.5 \%$ solution $)+2 \mathrm{ml}$ normal saline. In dexamethasone group bupivacaine $140 \mathrm{mg}(28 \mathrm{ml}$ of $0.5 \%$ solution $)+$ dexamethasone $8 \mathrm{mg}$ ( $2 \mathrm{ml} \mathrm{of} 4 \mathrm{mg} / \mathrm{ml}$ of solution). The primary outcome was the time to first analgesic requested in post-anaesthesia care unit. Numerical variables were compared by the student's t-test or mann-whitney U-test, depending on the distribution.

Result: Dexamethasone significantly prolonged the duration of analgesia. The duration of analgesia with bupivacaine was [mean $\pm S D$ ] $395 \pm 47.25$ ( $\mathrm{min}$ ) and with dexamethasone and bupivacaine was $718 \pm 57.14$ (min). There was significant difference between the postoperative VAS scores of the two groups at the time period of 6 hrs and $12 \mathrm{hrs}$ postoperatively. In $18 \mathrm{hrs}$. and $24 \mathrm{hrs}$, there was also significant difference in onset of sensory blockade [dexamethasone $(9.67 \pm 1.12 \mathrm{~min})$ vs bupivacaine $(12.72 \pm 1.39$ min. $), P$ vale 0.00 ] but there was no significant difference in onset motor and duration of motor blockade.

Conclusion: Dexamethasone when added to $0.5 \%$ bupivacaine in interscalene brachial plexus block in shoulder and arm surgeries, there was in early onset and prolongation of sensory analgesia and provides better postoperative analgesia.
\end{abstract}

Keywords: Peripheral nerve block, interscalene block, bupivacaine, dexamethasone, vas score

\section{INTRODUCTION}

Peripheral nerve block being used as the sole anaesthetic technique to facilitate painless surgery supplemented with monitored anaesthesia care. They offer better and longer pain relief and are becaming popular for ambulatory anaesthesia. Ambulatory surgery becaming increasingly desirable because it offers massive economic advantage, much more comfortable and convenient to the patient. It plays a major role in day care surgeries where top priority of success are : alertness, ambulation, analgesia and alimentation.It is safer in high risk patients with cardiopulmonary diseases, diabetes or other chronic illness as it minimally disturbs coronary hemodynamics and also blunts the stress response to the surgery. Grave complications of general anaesthesia like vomiting and aspiration, where patients are considered to be full stomach, are avoided.

Numerous techniques for injecting local anaesthetic into brachial plexus had been described. These are: interscalene - Winnie[1] , supraclavicular - kulenkampff [2], axillary - hirshchel .[3]

Investigators had tried, mixing local anaesthetic with adjuvant drugs in an attempt to prolong analgesia from nerve blocks. Adjuvants including epinephrine, clonidine opioids ,ketamine,and midazolam had met with limited success. However, the glucocorticoid dexamethasone appeared to be effective in a small number of preclinical [4,5] and clinical studies. [6]

Aims of present study was to determine the effect of dexamethasone when added to bupivacaine, on onset, duration of sensory blockade, motor blockade and to evaluate their side effects. interscalene approach for brachial plexus block was used in this study.

\section{Methods}

It was a randomized, double blind, interventional type, hospital based controlled study. In this study 60 patients (age 25-60 years) were included who underwent elective surgery in upper limb, with permission from the institutional ethical committee and review board and written informed patients consent was obtained. 
American Society of Anaesthesiologists (ASA) class I and II patients undergoing elective surgery of shoulder and arm were included in the study.We excluded patients who had not filling for these criteria, Patients not willing to participate in the study, uncooperative, local pathology at site of injection, history of convulsion, allergy to the drug used, severe neurological deficit, ASA Class III or above, systemic use of corticosteroid for 2 weeks or longer within 6 month of surgery were excluded from this study.

A detailed pre-operative check-up including general examination and systemic examination of the patient was carried out. Subjects were randomised with a 1:1 allocation ratio. the allocated intervention was written on a slip of paper, placed in serially numbered, opaque envelopes and sealed. As consecutive eligible subjects got enrolled, the envelopes were serially opened and the allocated intervention was implemented. Subjects were followed from the point of randomisation until complete recovery. The numbers of patients were equally distributed in both groups.

In control group 30 patients received bupivacaine $140 \mathrm{mg}(28 \mathrm{ml}$ of $0.5 \%$ solution $)+2 \mathrm{ml}$ normal saline and in dexamethasone group 30 patients received bupivacaine $140 \mathrm{mg}(28 \mathrm{ml}$ of $0.5 \%$ solution $)+$ dexamethasone $8 \mathrm{mg}$ ( $2 \mathrm{ml}$ of $4 \mathrm{mg} / \mathrm{ml}$ of solution) .

On the arrival of the patient in operation theatre room, all vital parameters such as heart rate (HR,) systolic blood pressure (SBP), diastolic blood pressure (DBP), and oxygen saturation (SpO2\%) were recorded . The site of injection was shaved and disinfected. The injection site was infiltrated with $1 \mathrm{ml}$ of lidocaine $2 \%$ subcutaneously and during injection, negative aspiration was performed every 6.5-7.0 ml to avoid intravascular injection. After interscalene block, vital parameter, onset of sensory and motor block, supplementary drugs use and complication were taken every $15 \mathrm{~min}$. until the completion of the procedure. Sensory block was assessed by loss of sensation to pinprick over the deltoid muscle. Motor block was assessed by failure to abduct the shoulder, the so-called 'deltoid sign'. and VAS score, vital parameter and complication recorded every 30 min. after post operatively. All blocks were performed by attending anaesthesiologists skilled in the interscalene approach.

The severity of postoperative pain was assessed by a blinded study team member using a verbal response score(VRS). Patients reporting pain score (VAS ) >4 analgesic were given by blinded observer. Data collected included time of block duration ( defined as time from the onset of sensory block to the first administration of supplemental analgesic medication after block), maximum VRS with rest and movement, and total opioid consumption.

Results were expressed as mean \pm SD (SEM). Demographic and haemodynamic data were subjected to statistical analysis by using two sample $t$-tests. For statistical analysis of modified lovett rating scale, VAS not normally distributed, a non-parametric test "Wilcoxon Mann Whitney test" was applied. The time of recovery of sensation and adverse effects were analyzed by the Chi square test/Fisher"s exact test. Intra-group comparison was performed using repeated measure ANOVA. A $P$-value $<0.05$ was considered statistically significant.

\section{Result}

Sixty patients were included in this study, thirty patients in each group. The groups of patients were comparable with respect to patient age, weight, and duration of surgery(table no. 1). The onset of sensory blockade was significantly more rapid in the dexamethasone group $(9.67 \pm 1.12$ vs. $12.72 \pm 1.39$ minutes respectively) than in the control group. The duration of sensory blockade was also significantly longer in the dexamethasone group $(718 \pm 57.14$ vs. $395 \pm 47.25$ minutes respectively) than in the control group.

There was no significant difference in the onset and duration of motor blockade (table no. 2 )in study. We also founded a significant difference between the postoperative VAS scores between two groups, at the time interval of $6 \mathrm{hrs}$ and $12 \mathrm{hrs}$ postoperatively. This can be expected as the mean duration of analgesia with plain bupicaine alone just exceeded of $6 \mathrm{hrs}(395 \pm 47.25 \mathrm{~min})$ and bupivacaine with dexamethasone falled just short of $12 \mathrm{hrs}(718 \pm 57.14 \mathrm{~min})$. In $18 \mathrm{hrs}$.and $24 \mathrm{hrs}$, there was no significant difference in VAS scores (table no. 2 ). This indicates that, the dexamethasone produced a significantly early onset and prolonged the duration of analgesia ,as compared to local anaesthetic bupivacaine alone. There was no significant difference in the vital parameters during surgery.

\section{Discussion}

Very few study are made to examine the effect of dexamethasone on plain bupivacaine for interscalene blocks. Our study was also unique, in that we designed it to detect a modest interaction between dexamethasone and the particular local anaesthetic used-an interaction that proved to be both statistically significant and clinically important.

Our study showed that addition of $8 \mathrm{mg}$ of dexamethasone to bupivacaine for interscalene brachial plexus block resulted in a significantly shorter in onset time and a significantly prolonged duration of sensory blockade. We also founded a significant difference between the postoperative VAS scores between 
these two groups at the time interval of $6 \mathrm{hrs}$ and $12 \mathrm{hrs}$ postoperatively. There appeared to be wide discrepancy in the duration of analgesia and sensory onset times, which may be explained by varying protocols of studies and different routes, end point for duration of analgesia, dose of dexamethasone and techniques of administration of block.

In contrast to other study, in our study there was no significant difference in the onset and duration of motor blockade with or without the usage of dexamethasone with bupivacaine The reason for this is obscure. This needs to be re-examined in subsequent studies.

Other studies had also demonstrated that addition of dexamethasone to bupivacaine microspheres prolonged the duration of blockade of the peripheral nerves. [5] Dexamethasone in bupivacaine microspheres also prolonged local analgesia when injected subcutaneously[7] and in intercostal nerve blockade.[8] Dexamethasone had also founded to enhance the analgesia of intravenous regional anaesthesia (IVRA) and reduce postoperative analgesic requirement.[9] The mechanism of dexamethasone-induced prolongation of peripheral nerve blockade is not well understood. Dexamethasone alone does not exhibit analgesic effects when incorporated into microspheres.[10] It commonly attributed to its anti-inflammatory action. This is supported by the finding that the degree of block prolongation had the same rank order as the relative anti-inflammatory potencies of glucocorticoids and is completely reversed by administration of a specific glucocorticoid receptor antagonist.[11] These effects are, therefore, mediated via the classic glucocorticoid receptor and are local

effects rather than systemic since incorporation of dexamethasone had not showned to alter kinetics of bupivacaine release from microcapsules.[10] Action on glucocorticoid receptor was proposed to alter the functioning of ion channels or produce local acidosis in nerve cell, thereby reducing the concentration of local anaesthetic required to produce conduction failure or trapping the highly ionised bupivacaine molecule into the neuronal cell. [8,11] Both these events would produce an extended action of local anaesthetics. Although the mechanism of action of glucocorticoids in backache (as epidural steroid injection) and facet syndrome may be due to inhibition of phospholipase A2, it appears that this may not be the mechanism in peripheral nerve blockade given the rapid onset of action of dexamethasone in such blocks.

Corticosteroids reduce conduction in nociceptive $\mathrm{C}$ fibres in an animal model.[12] It had been showned that onset of this effect was instantaneous and persisted for the duration of the steroid application. This concern that benzyl alcohol in commercial preparations of methylprednisolone could have contributed to the prolongation of axillary brachial plexus block.[7,13] Alcohol is frequently used for neurolytic nerve blocks and is toxic to nerves. In our study, the dexamethasone preparation did not contain benzyl alcohol.

\section{Conclusion}

Dexamethasone when added to $0.5 \%$ bupivacaine in interscalene brachial plexus block in upper limb surgeries, there was early onset and prolonged sensory analgesia and provided a better postoperative analgesia, hence the patient remains more comfortable in the postoperative period, with considerable therapeutic and economic benefit and without any potential side effects. It is useful in day care surgeries of shoulder and arm surgery. Further studies are required to elucidate the onset and duration of motor blockade of dexamethasone.

\section{References}

[1]. Winnie AP. Interscalene brachial plexus block. Anesthesia\& Analgesia 1970 May-Jun;49(3):455-66.

[2]. Kulenkampff, D (1911). "Zuranästhesierung des plexus brachialis [On anesthesia of the brachial plexus]" (in German). Zentralblatt fur Chirurgie 38: 1337-40.

[3]. G.Hirschel, "Anesthesia of the brachial pleaxus for operations on the upper," München Med Wochenschr, vol. 58, pp. 1555-1556, 1911.

[4]. Colombo G, Padera R, Langer R, Kohane DS. Prolonged duration local anesthesia with lipid-protein-sugar particles containing bupivacaine and dexamethasone. J Biomed Mater Res A 2005; 75: 458-64

[5]. Drager C, Benziger D, Gao F, Berde CB.Prolonged intercostal nerve blockade in sheep using controlled-release of bupivacaine and dexamethasone from polymer microspheres.Anesthesiology 1998; 89: 969-79

[6]. Benzon HT, Chew T-L, McCarthy RJ, Benzon HA, Walega DR. Comparison of the particle sizes of different steroids and the effect of dilution: a review of the relative neurotoxicities of the steroids. Anesthesiology 2007; 106: 331-8

[7]. Hotte K, Werner MU, Lacouture PG, Kehlet H. Dexamethasone prolongs local analgesia after subcutaneous infiltration of bupivacaine microcapsules in human volunteers. Anesthesiology 2002;96:1331-5.

[8]. Kopacz DJ, Lacouture PG, Wu D, Nandy P, Swanton R, Landau C. The dose response and effects of dexamethason on bupivacaine microcapsules for intercostal blockade (T9 toT11) in healthy volunteers. Anesth Analg 2003;96:576-82.

[9]. Bigat Z, Boztug N, Hadimioglu N, Cete N, Coskunfirat N, Ertok E. Does dexamethasone improve the quality of intravenous regional anesthesia and analgesia? A randomized, controlled clinical study. Anesth Analg 2006;102:605-9.

[10]. Castillo J, Curley J, Hotz J, Uezono M, Tigner J, Chasin M, et al. Glucocorticoids prolong rat sciatic nerve blockade in vivo from bupivacaine microspheres. Anesthesiology 1996;85:1157-66.

[11]. Curley J, Castillo J, Hotz J, Uezono M, Hernandez S, Lim J, et al.Prolonged regional nerve blockade: Injectable biodegradable bupivacaine/polyester microspheres. Anesthesiology 1996;84:1401-10.

[12]. Johansson A, Hao J, Sjolund B. Local corticosteroid application blocks transmission in normal nociceptive C-fibers. Acta Anaesthesiol Scand 1990;34:335-8. 
[13]. Lipman ZJ, Isaacson SA. Potentially concerning reason why adding methylprednisolone to local anesthetic may increase the duration of axillary block. Reg Anesth Pain Med 2005;30:114-5.

Table no 1 Demography

\begin{tabular}{|l|l|c|l|}
\hline & $\begin{array}{l}\text { Control group (plain } \\
\text { Bupivacaine ) }\end{array}$ & $\begin{array}{c}\text { Dexamethasone group } \\
\text { (Bupivacaine } \\
\text { +Dexamethasone ) }\end{array}$ & P value \\
\hline Age (years \pm SD ) & $35.23 \pm 13.25$ & $38.03 \pm 15.11$ & 0.44 \\
\hline Body weight $(\mathrm{kg} \pm$ SD) & $59.33 \pm 6.54$ & $59.14 \pm 5.58$ & 0.90 \\
\hline $\begin{array}{l}\text { Duration of surgery } \\
\text { (min.+SD) }\end{array}$ & $67.38 \pm 13.92$ & $66.18 \pm 11.39$ & 0.71 \\
\hline
\end{tabular}

Table no. 2 Comparison of motor, sensory and VAS score in groups

\begin{tabular}{|l|l|l|l|}
\hline & $\begin{array}{l}\text { Control group (plain } \\
\text { Bupivacaine ) }\end{array}$ & $\begin{array}{l}\text { Dexamethasone group } \\
\text { (Bupivacaine } \\
\text { +Dexamethasone })\end{array}$ & P value \\
\hline $\begin{array}{l}\text { Onset of motor } \\
\text { block(min._SD) }\end{array}$ & $20.67 \pm 2.32$ & $19.57 \pm 2.28$ & 0.069 \\
\hline $\begin{array}{l}\text { Onset of sensory } \\
\text { block(min. } \pm \text { SD) }\end{array}$ & $12.72 \pm 1.39$ & $9.67 \pm 1.12$ & 0.000 \\
\hline $\begin{array}{l}\text { Duration of motor } \\
\text { block(min.+SD) }\end{array}$ & $327 \pm 35.83$ & $345 \pm 33.96$ & 0.0505 \\
\hline $\begin{array}{l}\text { Duration of sensory } \\
\text { block(min.+SD) }\end{array}$ & $395 \pm 47.25$ & $718 \pm 57.14$ & 0.000 \\
\hline VAS score at 6 hr. & $1.55 \pm 0.31$ & $0.24 \pm 0.33$ & 0.000 \\
\hline VAS score at 12 hr. & $5.50 \pm 0.67$ & $2.03 \pm 1.00$ & 0.000 \\
\hline VAS score at 18 hr. & $6.32 \pm 1.07$ & $5.94 \pm 1.18$ & 0.19 \\
\hline VAS score at 24 hr. & $6.22 \pm 1.00$ & $5.78 \pm 0.94$ & 0.08 \\
\hline
\end{tabular}

